\title{
Journal of Material Science \& Engineering
}

\section{Transition Temperature Behaviour in Pan Based Composite Materials with and without SIC Filler}

\author{
Venkateswara Rao $\mathrm{CH}^{1 *}$, Usha Sri $\mathbf{P}^{1}$ and Ramanarayanan $\mathbf{R}^{2}$ \\ ${ }^{1}$ Mechanical Engineering Department, UCE, Osmania University, Hyderabad, India \\ ${ }^{2} T O$ 'D', ACC, Advanced Systems Laboratory, DRDO, Hyderabad, India
}

\begin{abstract}
This article focus on the study of Transition or Back wall Temperature behavior in PAN based composite materials with and without Silicon Carbide filler was investigated. PAN fabric is one of the most useful reinforcement materials in the composites, its major use being the manufacture of components in aerospace, automotive and missile technology. In this study, PAN carbon fabric laminates were prepared by Hand lay-up technique with and without Silicon Carbide filler. The experimental work was done on studying the Transition or Back wall Temperature characterization and ablative studies through Oxy-acetylene testing. The study results revealed that it exhibits the better thermal protection shield in PAN based Silicon Carbide filler laminate compared without adding filler material. However, the ablation rate study results were exhibits better erosion rate of CP laminate with Sic filler for thermal insulation.
\end{abstract}

Keywords: PAN carbon fabric; Phenolic resin; Silicon carbide (SIC) filler; Hand lay-up technique; Oxy-acetylene flame

\section{Introduction}

In aerospace application the re-entry vehicle structures are generally made of a structural member and thermal protection member made by the combination of Carbon/ Epoxy (CE) and over above Carbon/Phenolic (CP). For optimum performance of electronic packages mounted inside the $\mathrm{CE}+\mathrm{CP}$ shell, the temperature inside the shell should be ideally be less than $100^{\circ} \mathrm{C}$. The major objective of this study the back wall temperature of Carbon-Phenolic laminate with and without Silicon Carbide filler laminates.

The study of back wall temperature represents an understanding of that material which was selected when subjected to high temperature under a specific time period, what would be its back wall temperature so as to assess its suitability for its intended use. Since, advanced composite materials are very widely used in aerospace applications because of its exotic properties. The final materials would be able to form complex shapes and should be as light as possible.

This paper describes the preparation of laminate, cutting of samples and Oxy-acetylene flame test. For this study carbon/phenolic material is selected and silicon carbide powder (SIC) as filler material. Carbon fabric (PAN based) is used as reinforcement and phenolic resin is used as matrix, Sic filler is mixed with resin.

\section{Materials and Methods}

The experimental study was carried out to know the back wall temperature of the Carbon Phenolic Laminate with and without Silicon carbide filler. The PAN based carbon fabric impregnated with Phenolic resin with and without Sic as filler. Raw materials used in this work are PAN carbon plain wave woven fabric as $0 / 90$ fiber orientation. The adhesion made from Phenolic resin grade ABRON-PR100 (WS). Thickness of cloth is measuring $0.28-0.38 \mathrm{~mm}$. In this experiment PAN carbon fabric along with Phenolic resin laminates are prepared with Silicon Carbide powder used as filler. The Laminates are prepared with and without filler material and subjected to Oxy-acetylene testing. The following Table 1 describes the raw material constituents used for this experiment.

\section{Carbon fabric}

Poly Acrylo Nitrile (PAN) based Phenolic Composites are gradually becoming the most advanced materials having better properties to meet the Thermal requirements. The aerospace or missiles structures are require high strength, light weight and should withstand the high temperatures. Phenolic based composites are widely used as thermosetting resins having the better Thermal properties [1]. Composite materials are used to replace the conventional materials almost in every field of application. PAN based phenolic composites are widely used in air frame structures for aerospace and missile application due to their exotic properties such as low weight to high strength and also withstanding higher temperatures $[1,2]$. The thermal properties of carbon phenolic reinforced composites depending on the properties of ingredients used in the material.

\section{Phenolic resin}

Phenolic resins are the oldest synthetic polymers used commercially available of ABRON-PR100 (WS) Phenolics to meet the requirement for low smoke and toxicity. Phenolics are formed by the reaction of phenol (carbolic acid) and formaldehyde and catalyzed by an acid or base. Phenolics generally dark in colour and therefore used for applications in which colour does not matter [3]. The phenolic products are usually red, blue, brown or black in colour. These thermo set resins have typically been cured at high temperatures and usually high pressures $[2,4,5]$. Phenolic resin provides intermolecular hydrogen bonding as a domain driving force to interact with hydroxyl, carbonyl, amide, ester, and other hydrogen bonding functional groups.

\section{Silicon carbide filler}

Silicon Carbide (Sic) Fillers affect the tribological behaviour of the polymers and change the properties of the composite materials [4]. The present investigation has been concentrated to determine the back wall

*Corresponding author: Venkateswara Rao $\mathrm{CH}$, Ph.D Scholar, Mechanical Engineering Deptartment, UCE, Osmania University, Hyderabad, India, Tel: 8985420584; E-mail: hvenkateswararao@rediffmail.com

Received October 05, 2015; Accepted April 07, 2016; Published April 17, 2016

Citation: Venkateswara Rao CH, Usha Sri P, Ramanarayanan R (2016) Transition Temperature Behaviour in Pan Based Composite Materials with and without SIC Filler. J Material Sci Eng 5: 245. doi:10.4172/2169-0022.1000245

Copyright: (c) 2016 Venkateswara $\mathrm{Rao} \mathrm{CH}$, et al. This is an open-access article distributed under the terms of the Creative Commons Attribution License, which permits unrestricted use, distribution, and reproduction in any medium, provided the original author and source are credited. 
temperature on the carbon phenolic laminate with and without Sic filler by using Oxy-acetylene flame.

\section{Preparation of Laminate}

For preparation of laminate the carbon fabric is impregnated with phenolic resin (equivalent weight of reinforcement) and the phenolic resin is applied uniformly on the reinforcement and it is allowed for some time for solvent to evaporate. Then this prepregs are cut into size $(250 \times 250 \mathrm{~mm})$ and 10 layers of these prepregs are cut and kept ready. Then the mould is cleaned thoroughly and release agent (wax polish/ petroleum jelly) is applied uniformly over the mould for easy removal of laminate from the mould after curing. Then the cut prepregs are placed in the mould one over the other till all the 12 layers are placed in the mould refer the Figure 1a-1c. The mould is kept in a vacuum bag and cured in the autoclave by a cure cycle of temperature Vs time under vacuum and pressure.

Two laminates are prepared as per the above procedure. First laminate carbon fabric + phenolic resin without any filler is made and it is designated as Laminate $\mathrm{L}_{1}$. The second laminate carbon fabric + phenolic resin with Sic filler (20\%) added is made and it is designated as Laminate $\mathrm{L}_{2}$.

\section{Preparation of test specimen}

The laminates are taken out of the autoclave are to be cut into required sizes as per standard i.e $250 \times 250 \times 3 \mathrm{~mm}$ square were cut using a tile saw. Two specimens were cut in each category stated with and without Sic filler. The thermocouple is bonded in center of the test specimen from the rear surface with help of the high temperature adhesive cerma bond and subjected to Oxy-acetylene flame test.

\section{Testing of specimen on oxy-acetylene test bed}

The oxyacetylene test bed (OTB) is a small scale experimental setup to know the transition or back wall temperature of the said test laminates. The oxy-acetylene flame capable of producing a flame temperature up to $3000^{\circ} \mathrm{C}$ using a calibrated oxyacetylene welding torch. This type of experimental setup is used for testing the composite materials at relatively low costs while still simulating extreme conditions in real time applications $[4,5]$.

OTB setup contains a data acquisition system to measure the in situ temperature of the test specimens using embedded thermocouples. Test sample of $4^{\prime} \times 4^{\prime}$ is held on the fixture, and oxy acetylene torch is held at a predetermined distance $(\mathrm{d}=10 \mathrm{~cm})$ in front of the laminate focusing at the center. The torch is lit and the sample is subjected to exposure for more than 1 minute and the back wall temperature recorded for the said laminates refer the Figure $2 \mathrm{a}$ and $2 \mathrm{~b}$.

\section{Results}

The comparative study has been carried out between the two laminates designated as Carbon Phenolic laminate without filler and Carbon Phenolic laminate with Silicon carbide filler. The test results were tabulated in the Tables 2 and 3 respectively.

\section{Laminate 1}

Type of laminate: Carbon phenolic prepeg without filler $\left(\mathrm{L}_{1}\right)$

Filler: No filler

Flame temperature: 3000 centigrade

\section{Laminate 2}

Type of Laminate: Carbon phenolic prepeg with filler $\left(\mathrm{L}_{2}\right)$

Filler: Silicon Carbide ${ }^{*} 220$ mesh

Percentage of filler: $\% 20$ Sic

Flame temperature: 3000 centigrade

\section{Ablation properties}

The Erosion was measured after the tests refer the Figure $3 \mathrm{a}$ and $3 \mathrm{~b}$, and it is tabulated as given below in Table 4 .

\section{Discussion}

The Transition or back wall temperature of the samples are measured, by focusing the thermal beam set up located perpendicular to the sample surface. The graphical representation of the two laminates shown in Figure 4.

The investigation revealed that Carbon Phenolic laminate with Silicon carbide filler exhibits the better transition temperature compared without adding the Sic filler material. The graphical representation of the ablation rate study of the Carbon Phenolic laminate with and without Sic filler. The ablation rate test results are revealed that Carbon Phenolic Laminate without Sic filler $\left(\mathrm{L}_{1}\right)$ shows the $0.8 \mathrm{~mm}$ erosion rate (erosion rate can be defined as rate at which the wearing of rocks and other deposits on the earth surface by the action of water, ice, wind take place.) is less than with Carbon Phenolic Laminate with Sic filler $\left(\mathrm{L}_{2}\right)$ shown as $0.1 \mathrm{~mm}$ erosion (Figure 5).

\begin{tabular}{|c|c|}
\hline Constituent & Grade \\
\hline Reinforcement & PAN carbon fabric T-300 \\
\hline Phenolic resin & ABRON-PR100(WS) \\
\hline Filler material & Silicon Carbide powder MW40.09 \\
\hline
\end{tabular}

Table 1: Details of materials used.

\begin{tabular}{|c|c|c|c|}
\hline SI No. & $\begin{array}{c}\text { Initial reading (ambient } \\
\text { temperature } \mathbf{t}_{\mathbf{0}} \text { ) }\end{array}$ & Time (Sec) & $\begin{array}{c}\text { Temperature } \\
\text { achieved } \mathbf{( T}_{\mathbf{A})}\end{array}$ \\
\hline 1 & 33 & 15 & 34 \\
\hline 2 & - & 30 & 57 \\
\hline 3 & - & 45 & 118 \\
\hline 4 & - & 60 & 192 \\
\hline 5 & - & 75 & 253 \\
\hline
\end{tabular}

Table 2: Represents carbon phenolic prepeg without filler.

\begin{tabular}{|c|c|c|c|}
\hline SI No. & $\begin{array}{c}\text { Initial reading (ambient } \\
\text { temperature } \mathbf{T}_{\mathbf{0}} \text { ) }\end{array}$ & Time (Sec) & $\begin{array}{c}\text { Temperature } \\
\text { achieved } \mathbf{( T}_{\mathbf{A})}\end{array}$ \\
\hline 1 & 33 & 15 & 52 \\
\hline 2 & - & 30 & 88 \\
\hline 3 & - & 45 & 96 \\
\hline 4 & - & 60 & 100 \\
\hline 5 & - & 75 & 105 \\
\hline
\end{tabular}

Table 3: Represents carbon phenolic prepeg with filler.

\begin{tabular}{|c|c|c|c|c|}
\hline SI. No & Nomenclature & $\begin{array}{c}\text { Thickness } \\
\text { before test } \\
(\mathbf{m m})\end{array}$ & $\begin{array}{c}\text { Thickness } \\
\text { after test } \\
(\mathbf{m m})\end{array}$ & $\begin{array}{c}\text { Erosion } \\
\mathbf{( m m})\end{array}$ \\
\hline 1 & Laminate $\mathrm{L}_{1}$ & 3.00 & 2.2 & 0.8 \\
\hline 2 & Laminate $\mathrm{L}_{2}$ & 3.00 & 2.9 & 0.1 \\
\hline
\end{tabular}

Table 4: Shows erosion rate. 
Citation: Venkateswara Rao CH, Usha Sri P, Ramanarayanan R (2016) Transition Temperature Behaviour in Pan Based Composite Materials with and without SIC Filler. J Material Sci Eng 5: 245. doi:10.4172/2169-0022.1000245

\section{Conclusion}

The Test samples were successfully manufactured with Phenolic resin, PAN based carbon fabric with and without Silicon carbide filler by hand layup technique. The test samples were subjected to Oxy-acetylene flame test and test results are revealed that the Carbon Phenolic laminate with Silicon carbide filler exhibits the better transition temperature behavior compared without Silicon carbide filler laminate comparatively withstood the high temperature during ablation test. The CP laminate with Sic filler exhibits the better erosion rate than other laminate without filler. The addition of Sic filler improved the better temperature withstanding ability in the laminate and it is the best composite laminate for thermal insulation.

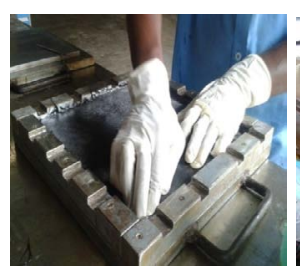

(a)

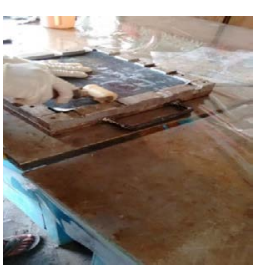

(b)

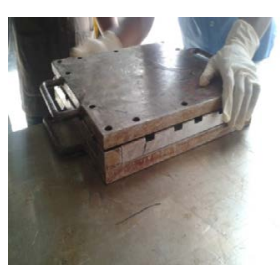

(c)
Figure 1: (a-c) Represents the preparation of laminate by hand layup technique.
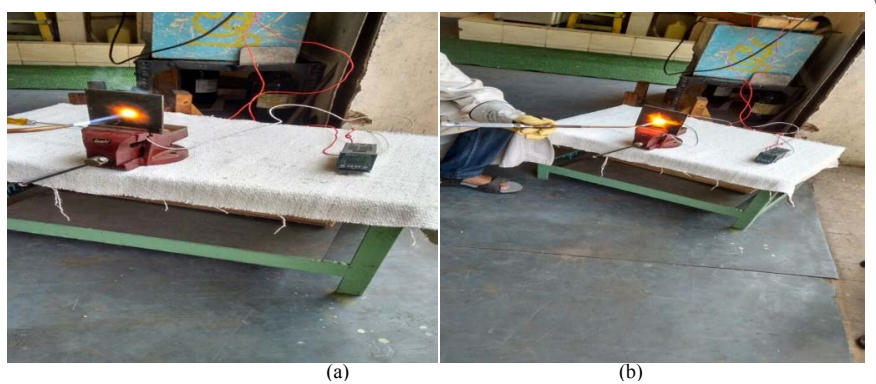

Figure 2: $(a$ and b) Represents the oxy-acetylene test bed setup.
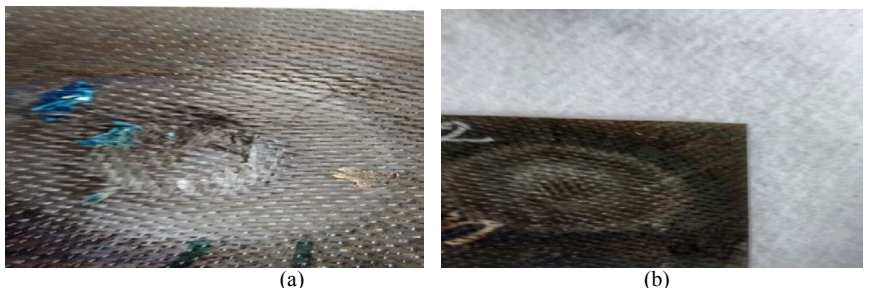

Figure 3: $(a$ and $b)$ Represents the post test samples.

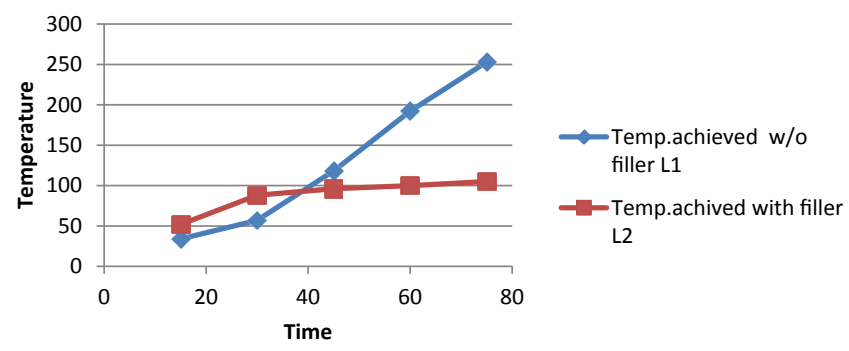

Figure 4: Graphical representation of comparative transition study of two laminates.

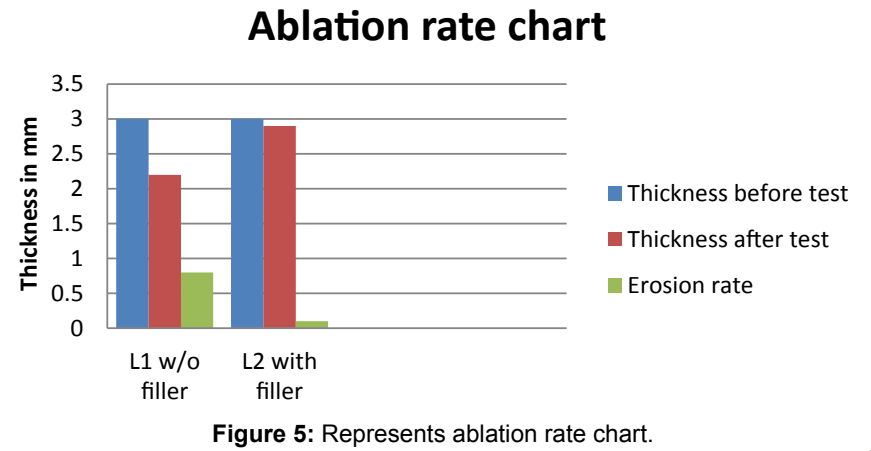

\section{References}

1. Mallick PK (1993) Fiber Reinforced Composites: Materials, Manufacturing and Design. (3rdedn) Marcel Dekker Inc, New York.

2. Tate JS, Gaikwad S, Theodoropoulou N, Trevino E, Koo JH (2013) Carbon/ Phenolic Nano composites as Advanced Thermal Protection Material in Aerospace Applications. Journal of Composites.

3. Torre L, Kenny JM, Maffezzoli AM (1998) Degradation behavior of a composite material for thermal protection systems. Journal of Materials Science 33: $3137-$ 3143.

4. Devendra K, Rangaswamy $\mathrm{T}$ (2012) Determination of mechanical properties of $\mathrm{Al}_{2} \mathrm{O}_{3}, \mathrm{Mg}(\mathrm{OH})_{2}$ and Sic. filled E-glass epoxy composites. Int J Engg Res App 2: 2028-2033.

5. Pulci G, Tirillò J, Marra F, Fossati F, Bartuli C, et al. (2010) Carbon-phenolic ablative materials for re-entry space vehicles: manufacturing and properties. Composites A 41: 1483-1490. 